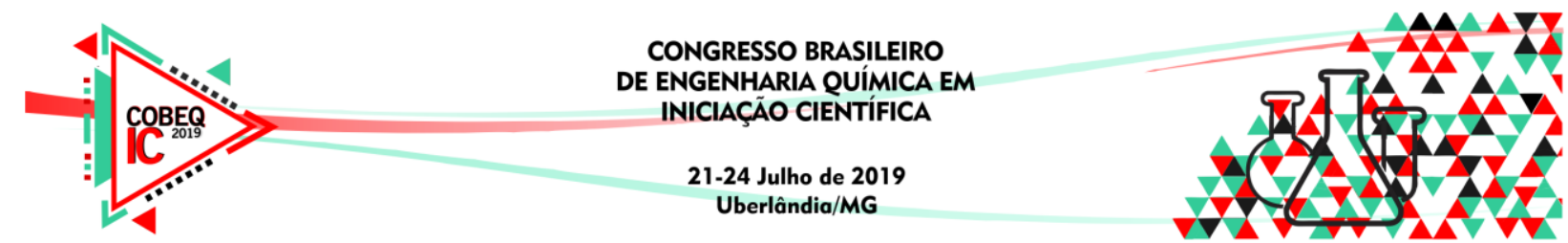

\title{
PRODUÇÃO DE BIODIESEL A PARTIR DE ÓLEO RESIDUAL DE FRITURA: VIABILIDADE DE ROTAS
}

\author{
B.B. SILVA ${ }^{1}$, A.C.M. MARINHO ${ }^{1}$, J.B. NEVES ${ }^{1}$ e P. C. NETO ${ }^{1}$ \\ ${ }^{1}$ Universidade Federal de Lavras, Departamento de Engenharia \\ E-mail para contato: bianca.silva@estudante.ufla.br
}

\begin{abstract}
RESUMO - Com o crescimento da demanda energética, combinado com as mudanças climáticas e a redução do suprimento de combustíveis fósseis surge a necessidade de substituí-los por alternativas sustentáveis. Neste trabalho, buscouse desenvolver a produção de biodiesel a partir de óleos residuais de fritura, os quais comumente não são descartados de forma adequada na natureza. Sendo assim, reutilizar este resíduo é ambientalmente correto e economicamente viável. Foram testadas duas metodologias de produção, sendo que a primeira rota consistiu principalmente na reação de esterificação seguida da transesterificação, sendo esta a reação do óleo com hidróxido de potássio em metanol, produzindo o biodiesel. Na segunda rota realizou-se somente a reação de transesterificação. Em seguida, foram feitas as análises de acidez, iodo, ponto de fulgor e massa específica para caracterização físico-química do biodiesel. Por fim, os dados obtidos foram comparados com os limites pré-estabelecidos pela ANP (Agência Nacional de Petróleo, Gás Natural e Biocombustíveis). Observou-se que o índice de acidez do biodiesel obtido através da Rota 1 foi de 0,2924 mg NAOH/g, menor que o limite estabelecido pela norma $(0,5 \mathrm{mg} \mathrm{NAOH} / \mathrm{g})$. Além disso, os demais parâmetros analisados também se encontraram de acordo com a ANP. Sendo assim, esta rota foi considerada a mais viável para produção, a qual pretende-se ampliar da escala laboratorial para escala piloto na usina do G-Óleo da Universidade Federal de Lavras.
\end{abstract}

\section{INTRODUÇÃO}

A matriz energética mundial é fortemente dependente do petróleo e seus derivados, que causam grandes problemas como a poluição do ar, mudanças climáticas e formação de resíduos tóxicos, além de que o suprimento destes combustíveis fósseis apresenta gradativa redução (PARENTE, 2003). Nesse cenário, os biocombustíveis apresentam potencial para reduzir a dependência do uso de combustíveis fósseis, abordar as questões de segurança dos combustíveis e do meio ambiente, além de favorecer alguns benefícios socioeconômicos, como desenvolvimento sustentável e geração de emprego (SANNA, 2014).

Uma das tecnologias alternativas mais promissoras é a utilização de biodiesel, que segundo a Lei 11.097/2005, é um combustível derivado de biomassa renovável para uso em motores a combustão interna com ignição por compressão, que possa substituir parcial ou totalmente o óleo diesel de origem fóssil. Esse biocombustível pode ser obtido de óleos vegetais, óleos residuais e gorduras animais. 


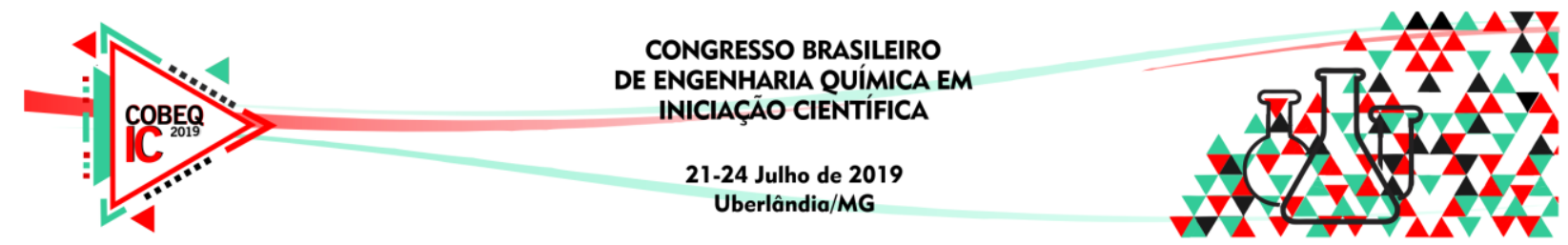

Visando o contexto ambiental e econômico, iniciaram-se pesquisas em relação aos óleos residuais de fritura como matéria prima deste combustível. O consumo de alimentos fritos aumentou consideravelmente, o que consequentemente aumenta a quantidade de resíduos gerados, sendo o principal o óleo de fritura, o qual não possui uma destinação adequada, causando desde o entupimento de tubulações até eutrofização de ambientes aquáticos (CASTENELLI, 2008; RAMOS e SILVA, 2011).

A produção completa do biodiesel envolve algumas etapas principais, como o pré tratamento do óleo, reação de esterificação, transesterificação e purificação do biodiesel obtido. A reação de esterificação é uma etapa opcional, que consiste em um processo de prétratamento da matéria prima para remoção dos ácidos graxos livres (SILVA, 2008), aumentando o rendimento da produção de biodiesel. Já na reação de transesterificação, o triglicerídeo presente no óleo vegetal reage com um álcool simples (metanol ou etanol) na presença de um catalisador, produzindo uma mistura de ésteres alquílicos de ácidos graxos (biodiesel propriamente dito), além de glicerol como subproduto (conhecido como glicerina, substância muito empregada na indústria farmacêutica e de cosméticos).

O presente trabalho teve como objetivo testar diferentes rotas de produção de biodiesel a partir de óleo de fritura residual fornecido pela Padaria X da cidade de Lavras. Na primeira rota realizou-se a reação de esterificação seguida da transesterificação, sendo esta última reação catalisada por hidróxido de potássio em metanol. A segunda rota constituiu somente da reação de transesterificação. Analisando a viabilidade técnica, será definida a melhor rota de produção com intuito de ser desenvolvida na usina-piloto do G-Óleo - UFLA, considerando quesitos como minimização do consumo e descarte de água das etapas de lavagem do óleo e do biodiesel.

\section{MATERIAIS E MÉTODOS}

\subsection{Coleta, caracterização e pré-tratamento da amostra do óleo residual de fritura}

O óleo residual utilizado nesta pesquisa foi fornecido pela Padaria $\mathrm{X}$ da cidade de Lavras e todo o projeto foi realizado no Laboratório de Química de Plantas Oleaginosas, Óleos, Gorduras e Biodiesel da Universidade Federal de Lavras, em pequena escala.

Foi realizada a caracterização do óleo bruto baseado na metodologia para óleos e gorduras do Instituto Adolfo Lutz (2008). Posteriormente fez-se a lavagem do óleo, com o intuito de remoção de impurezas, e o procedimento utilizado foi a degomagem com água. Aqueceu-se a amostra de óleo a $80^{\circ} \mathrm{C}$, adicionou-se $20 \%$ de água destilada, agitou-se no reator por cerca de 30 minutos a $400 \mathrm{rpm}$, e deixou-se decantando de um dia para o outro. Este processo foi feito duas vezes. Após, o óleo separado por decantação foi levado à estufa a vácuo a $70^{\circ} \mathrm{C}$, por 40 minutos a $25 \mathrm{mmHg}$, para secagem.

O óleo purificado foi caracterizado a partir da determinação do índice de acidez, saponificação, refração, massa específica, peróxido e iodo, baseado na metodologia para óleos e gorduras do Instituto Adolfo Lutz (2008). 


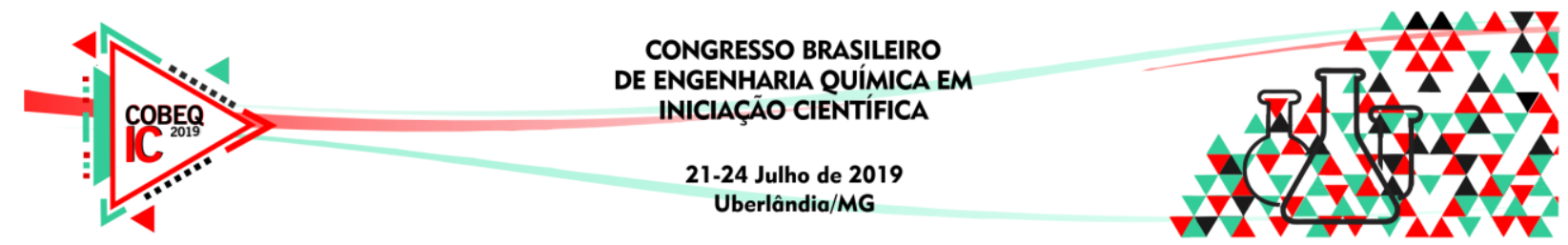

\subsection{Produção do biodiesel}

Para produção do biodiesel, recomenda-se realizar a esterificação antes da transesterificação, com intuito de diminuir a quantidade de ácidos graxos livres presentes no óleo. Mas devido ao baixo índice de acidez apresentado pelo óleo residual purificado, foram realizadas duas rotas, visando compará-las para determinar a mais viável. Na Rota 1 foi feita a esterificação seguida da transesterificação, e na Rota 2 foi feita a transesterificação direta.

As metodologias utilizadas partiram de adaptações de procedimentos encontrados na literatura, testados por graduandos membros do G-Óleo - UFLA. O teor de ésteres metílicos obtidos nestas condições serão posteriormente analisados por cromatografia em fase gasosa.

Rota 1 - Esterificação seguida de Transesterificação: Para realizar a esterificação, adicionou-se $250 \mathrm{ml}$ de óleo no reator encamisado, deixou-se agitando a uma temperatura de $90^{\circ} \mathrm{C}$ a $1100 \mathrm{rpm}$. Adicionou 50\% de metanol, medindo $125 \mathrm{ml} \mathrm{em} \mathrm{uma} \mathrm{proveta,} \mathrm{e} 3 \%(\mathrm{v} / \mathrm{v})$ de ácido fosfórico, ou seja $7,5 \mathrm{ml}$ que foi medido também em uma proveta. Deixou-se agitando por 3 horas. Transferiu-se para um funil de squib, conforme mostra a Figura 1. Após decantar, secou-se o óleo na estufa a vácuo por 40 minutos.

Figura 1 - Reação de esterificação do óleo residual purificado.

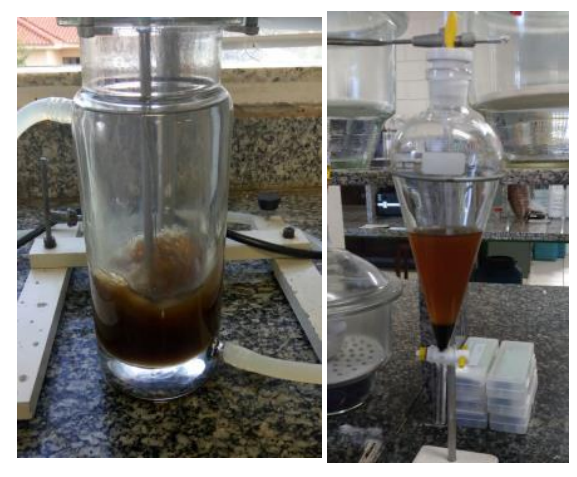

Dando sequência, para realizar a reação de transesterificação, adicionou-se $200 \mathrm{ml}$ de óleo no reator encamisado, aquecendo a $50^{\circ} \mathrm{C}$. Adicionou-se $25 \%$ de metanol e $2 \%$ de metilato de potássio $30 \%$. Ou seja, foram medidos $50 \mathrm{ml}$ de metanol, além de mais $4 \mathrm{ml}$ deste, que correspondem aos $2 \%$ necessários para preparar o metilato de potássio, catalisador utilizado. Para este preparo, pesou-se na balança analítica 1,2 gramas de $\mathrm{KOH}$, o qual foi solubilizado nos $4 \mathrm{ml}$ de metanol medidos. Agitou-se por 40 minutos a $500 \mathrm{rpm}$. A mistura foi transferida para um funil de squib para decantar. A Figura 2 mostra a mistura bifásica formada, biodiesel e glicerina. 


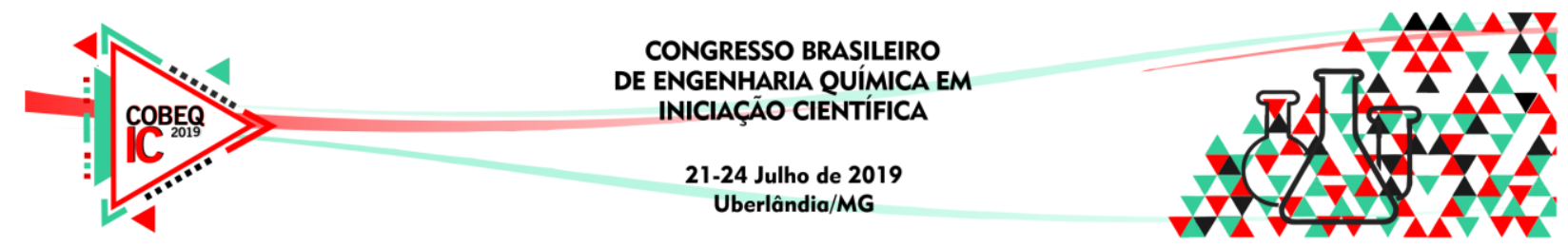

Figura 2 - Transesterificação após esterificação, com formação de biodiesel e glicerina, representada pela porção inferior do funil.

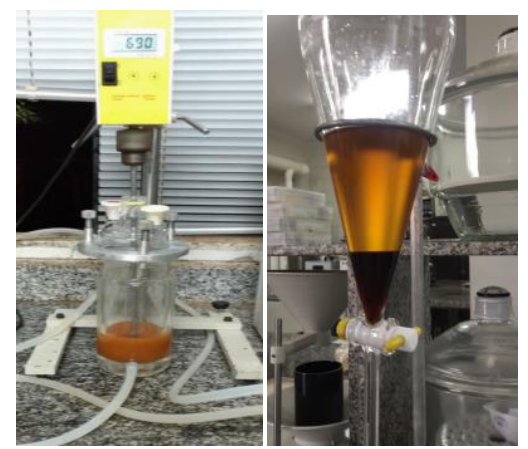

Rota 2 - Somente transesterificação: A mesma metodologia para reação de transesterificação descrita na Rota 1 foi utilizada na Rota 2, porém foi realizada logo após a etapa de secagem do óleo purificado. A Figura 3 mostra a mistura bifásica formada, biodiesel e glicerina.

Figura 3 - Somente transesterificação do óleo residual.

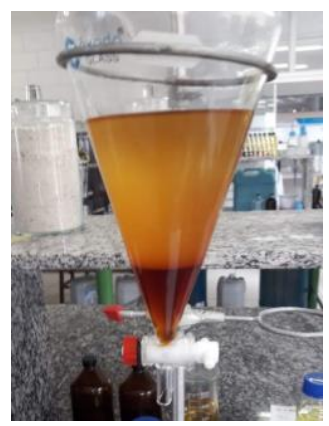

\subsection{Lavagem do biodiesel}

Com a finalidade de diminuir a quantidade de água utilizada na lavagem do biodiesel, foi feito um método de titulação utilizando ácido clorídrico, para determinar exatamente a quantidade de ácido necessária para neutralizar o caráter básico do produto, devido à presença de hidróxido de potássio.

Primeiramente, foi realizado o cálculo de $\mathrm{HCl}$ que seria utilizado para fazer esta purificação. Para isso, adicionou $5 \mathrm{~mL}$ do biodiesel produzido em um erlenmeyer de $125 \mathrm{ml}$. Acrescentou-se então, algumas gotas de fenolftaleína, e titulou-se utilizando uma solução de $\mathrm{HCl}$ até que a coloração rósea desaparecesse. Este procedimento foi realizado em triplicata. Em sequência, calculou-se a partir do volume da titulação, o número de mols de $\mathrm{HCl}$ gastos e a partir deste valor calculou-se o volume de ácido que seria usado na lavagem do biodiesel. Para este processo, esquentou-se água ultrafiltrada na proporção 1:1/2 até ferver. Colocou-se a mesma no borrifador junto à quantidade de $\mathrm{HCl}$ necessária, e borrifou nas paredes do béquer, enquanto o biodiesel estava sob agitação. Feito isso, transferiu-se o biodiesel para um funil de squib para decantar, e, logo após, o mesmo foi secado na estufa à vácuo a $70^{\circ} \mathrm{C}$. 


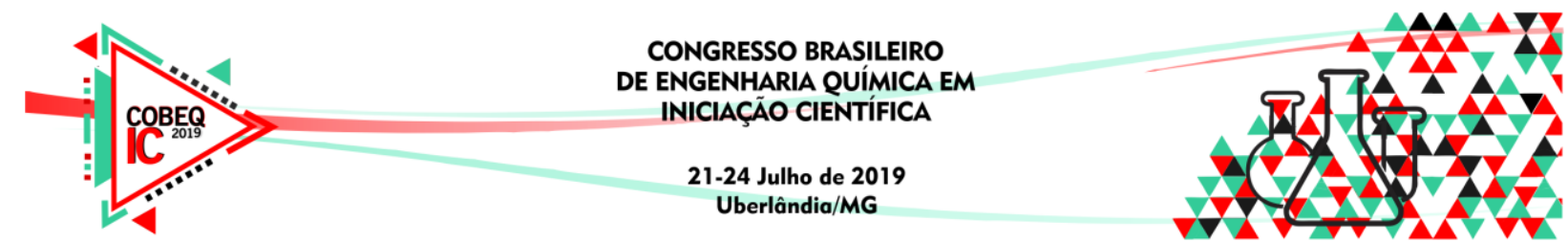

\subsection{Caracterização do biodiesel}

A última etapa da produção é a caracterização do biodiesel, etapa importante para verificação da concordância com as normas estabelecidas pela ANP (Agência Nacional do Petróleo, Gás Natural e Biocombustíveis). Foram determinados índice de acidez, massa específica a $20^{\circ} \mathrm{C}$ e iodo utilizando as metodologias do Instituto Adolfo Lutz (2008), e por fim, a determinação do ponto de fulgor utilizando o equipamento Vaso Fechado PenskyMartens.

\section{RESULTADOS E DISCUSSÕES}

\subsection{Caracterização do óleo purificado}

Foram realizadas análises para caracterização do óleo residual, que podem ser encontradas na Tabela 1, para o óleo purificado.

Tabela 1 - Caracterização do óleo purificado.

\begin{tabular}{|c|c|}
\hline Característica & Valor obtido \\
\hline \hline Saponificação & $75,99 \mathrm{mg}$ da base $/ \mathrm{g}$ do óleo \\
\hline Acidez & $2,15 \mathrm{mg} \mathrm{de} \mathrm{NAOH} / \mathrm{g}$ de óleo \\
\hline Refração & $1,475 \mathrm{nD} \mathrm{a} 21,7^{\circ} \mathrm{C}$ \\
\hline Massa Específica & $0,93 \mathrm{~g} / \mathrm{cm}^{3}$ \\
\hline Peróxido & $9,16 \mathrm{meq}$ por $1000 \mathrm{~g}$ de óleo \\
\hline Iodo & 57,79 \\
\hline
\end{tabular}

Segundo Gonçalves et al. (2009), o óleo deve conter uma acidez de no máximo $1 \mathrm{mg}$ $\mathrm{NAOH} / \mathrm{g}$ para que atenda a acidez normalizada pela ANP de $0,5 \mathrm{mg} \mathrm{NAOH} / \mathrm{g}$ para Biodiesel. Sendo assim, o óleo residual coletado para análises pode ser considerado um óleo de qualidade, pois a acidez obtida foi relativamente baixa. Estudos realizados em laboratório mostram que óleos que apresentam índice de acidez acima de $7 \mathrm{mg} \mathrm{NAOH/g}$, se submetidos a transesterificação via catálise básica para a produção de biodiesel reagem formando sabões.

\subsection{Produção do biodiesel}

Rota 1 - Esterificação seguida de Transesterificação: Foram realizadas análises de laboratório para estabelecer parâmetros comparativos do biodiesel obtido no experimento com os dados fornecidos pela Resolução ANP Nº 14, DE 11.5.2012. As análises realizadas foram acidez, massa específica a $20^{\circ} \mathrm{C}$, iodo e ponto de fulgor.

A massa específica da amostra de biodiesel do nosso experimento foi de $850,3 \mathrm{~kg} / \mathrm{m}^{3}$, valor coerente dentro da especificada, que é de $850-900 \mathrm{~kg} / \mathrm{m}^{3}$. O índice de iodo obtido foi de 58,98, parâmetro ainda não especificado pela literatura. $\mathrm{O}$ ponto de fulgor mínimo especificado é de $100^{\circ} \mathrm{C}$, e o obtido foi de $117^{\circ} \mathrm{C}$, valor próximo ao estabelecido. $\mathrm{O}$ índice de acidez obtido foi de $0,2924 \mathrm{mg} \mathrm{NAOH} / \mathrm{g}$, considerado o melhor resultado, pois é um valor consideravelmente baixo e está dentro do limite especificado pela ANP. 


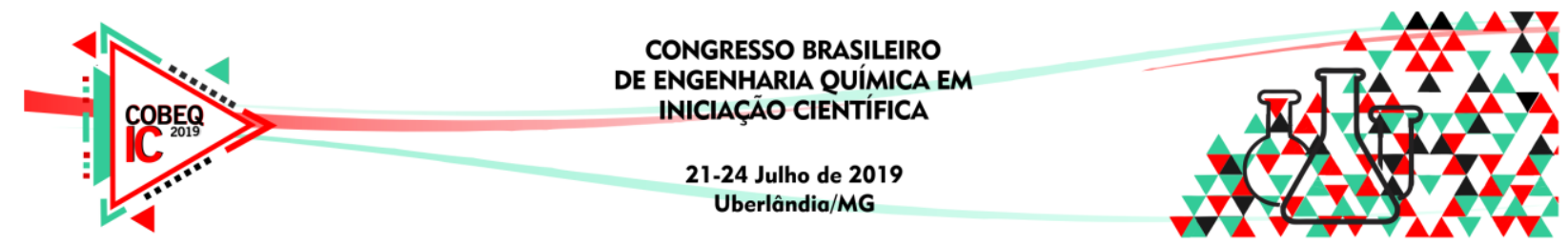

Rota 2 - Somente transesterificação: As análises realizadas a fim de comparar com os parâmetros fornecidos pela ANP foram índice de acidez, índice de iodo, massa específica a $20^{\circ} \mathrm{C}$ e ponto de fulgor.

Analisando-se os dados obtidos, concluiu-se que esta rota não é viável, considerando-se que o índice de acidez encontrado para a amostra de biodiesel foi de 0,6416 mg de NAOH/g de óleo, $28 \%$ maior que o valor máximo estipulado pela norma. As demais características condizem com os valores limites, sendo a massa específica de $859 \mathrm{~kg} / \mathrm{m}^{3}$, ponto de fulgor $100^{\circ} \mathrm{C}$ e iodo 41,99 .

\subsection{Lavagem do biodiesel}

A metodologia de lavagem testada foi eficiente, pois a quantidade de ácido clorídrico utilizada a partir dos cálculos foi suficiente para neutralizar o biodiesel com apenas uma lavagem, o que atingiu o objetivo esperado em evitar o gasto desnecessário de água durante o processo de purificação do produto.

\section{CONCLUSÃO}

A partir das análises efetuadas, é possível concluir que apesar do biodiesel ter sido formado em ambas as rotas, a rota mais viável e também a escolhida é aquela em que a esterificação é seguida da reação de transesterificação com $2 \%$ de metilato de potássio. Este processo de produção apresentou parâmetros que estão em acordo com os parâmetros estabelecidos pela ANP, o que torna possível a produção do biodiesel em escala piloto na universidade. Além disso, durante todo o processo buscou-se a melhor forma de otimizar e melhorar a produção e também evitar o desperdício de água e reagentes.

\section{RERÊNCIAS BIBLIOGRÁFICAS}

CASTENELLI C. A. Estudo da viabilidade de produção do biodiesel, obtido através do óleo de fritura usado, na cidade de Santa Maria, RS Dissertação (Mestrado de Engenharia de Produção), Área de Concentração em Qualidade e Produtividade, Universidade Federal de Santa Maria, Santa Maria, 2008.

GONÇALVES, A.; SOARES, J.;BRASIL, A. N.; NUNES, D. L. Determinação Do Índice De Acidez De Óleos e Gorduras Residuais Para Produção De Biodiesel. In: Congresso da rede brasileira de tecnologia de biodiesel, 3, 2009, Brasília. Anais... III Congresso da rede brasileira de tecnologia de biodiesel, Brasília, 2009, P. 187-188.

INSTITUTO ADOLFO LUTZ. Normas Analíticas do Instituto Adolfo Lutz. Métodos físico-químicos para análises de alimentos. $4^{\mathrm{a}} \mathrm{ed}$. (1ª Edição digital), 2008.

PARENTE, E. J. S.. Biodiesel: Uma aventura tecnológica num país engraçado. Fortaleza: Unigráfica, 2003.

SANNA, A. Advanced Biofuels from Thermochemical Processing of Sustainable Biomass in Europe. Bioenergy Research, 7, pp.36 47, 2014.

SILVA, F. R.; Wypych, F.; Ramos, L. P. Química Nova, 2011. 